\title{
Flaxseed Mitigates Acute Oxidative Lung Damage in a Mouse Model of Repeated Radiation and Hyperoxia Exposure Associated with Space Exploration
}

\section{Ralph A. Pietrofesa ${ }^{1}$, Charalambos C. Solomides ${ }^{2}$ and Melpo Christofidou-Solomidou ${ }^{1 *}$}

${ }^{1}$ Department of Medicine, Pulmonary Allergy and Critical Care Division, University of Pennsylvania, Philadelphia, PA 19104, USA

${ }^{2}$ Department of Pathology, Jefferson University Hospital, Philadelphia, PA 19140, USA

\begin{abstract}
Background: Spaceflight missions may require crewmembers to conduct extravehicular activities (EVA). Prebreathe protocols in preparation for an EVA entail 100\% hyperoxia exposure that may last for a few hours and be repeated 2-3 times weekly. Each EVA is associated with additional challenges such as low levels of total body cosmic/ galactic radiation exposure that may present a threat to crewmember health. We have developed a mouse model of total body radiation and hyperoxia exposure and identified acute damage of lung tissues. In the current study we evaluated the usefulness of dietary flaxseed (FS) as a countermeasure agent for such double-hit exposures.

Methods: We evaluated lung tissue changes 2 weeks post-initiation of exposure challenges. Mouse cohorts $(n=5 /$ group) were pre-fed diets containing either $0 \% \mathrm{FS}$ or $10 \% \mathrm{FS}$ for 3 weeks and exposed to: a) normoxia (Untreated); b) $>95 \% \mathrm{O}_{2}\left(\mathrm{O}_{2}\right)$; c) $0.25 \mathrm{~Gy}$ single fraction gamma radiation (IR); or d) a combination of $\mathrm{O}_{2}$ and IR $\left(\mathrm{O}_{2}+\mathrm{IR}\right) 3$ times per week for 2 consecutive weeks, where 8-hour hyperoxia treatments were spanned by normoxic intervals.

Results: At 2 weeks post challenge, while control-diet fed mice developed significant lung injury and inflammation across all challenges, FS protected lung tissues by decreasing bronchoalveolar lavage fluid (BALF) neutrophils $(p<0.003)$ and protein levels, oxidative tissue damage, as determined by levels of malondialdehyde (MDA) $(p<0.008)$ and nitrosative stress as determined by nitrite levels. Lung hydroxyproline levels, a measure of lung fibrosis, were significantly elevated in mice fed $0 \%$ FS $(p<0.01)$ and exposed to hyperoxia/radiation or the combination treatment, but not in FS-fed mice. FS also decreased levels of a pro-inflammatory, pro-fibrogenic cytokine (TGF-ß1) gene expression levels in lung.

Conclusion: Flaxseed mitigated adverse effects in lung of repeat exposures to radiation/hyperoxia. This data will provide useful information in the design of countermeasures to early tissue oxidative damage associated with space exploration.
\end{abstract}

Keywords: Bronchoalveolar lavage; Double-hit; extravehicular activity; Hyperoxia; Inflammation; Lung fibrosis; Acute lung injury; Mouse model; Nitrosative stress; Oxidative stress; Radiation pneumonopathy; Space exploration; TGF- $\beta 1$; Total body irradiation

Abbreviations: BALF: Bronchoalveolar Lavage Fluid' ELISA: Enzyme-linked Immunosorbent Assays; EVA: Extravehicular Activity; FI: Fibrotic Index; TBI: Total Body Irradiation; LP: Lipid Peroxidation; MDA: Malondialdehyde; NT: Nitrotyrosine; PMN: Polymorphonuclear Leukocyte; ROS: Reactive Oxygen Species; SEM: Standard Error Means; WBC: White Blood Cells; DCI: Decompression Illness

\section{Introduction}

Extravehicular activities (EVAs) for assembly and maintenance activities at the International Space Station (ISS) [1], or EVAs during interplanetary missions expose astronauts to challenges that may pose potential health risks [2-5]. Studies such as the MATROSHKA experiment $[6,7]$ was designed to determine, evaluate and if possible even foresee, as accurately as possible the radiation exposures that crew members will experience during such an EVA in order to minimize risks and to establish exposure limits. In addition to radiation exposure dangers, in order to prevent decompression illness (DCI), crewmembers undergo pre-breathing protocols that insure total body nitrogen stores are depleted prior to decompression. EVA risk is thus compounded by the potential health risk of repeated cycles of $100 \% \mathrm{O}_{2}$ exposure during pre-breathe procedures. Deleterious effects of hyperoxia combined with space-related exposures have long been recognized [8]. In addition, exposure to a unique spectrum of radiation including galactic cosmic radiation (GCR) and solar particle events (SPE) $[9,10]$ adds an additional environmental exposure in space that may affect lung tissue primed by hyperoxia during or after an EVA. Well-established flight rules ensure that acute oxygen toxicity is avoided, however, the long term effects on lung function of multiple EVAs and ensuing cyclic exposures to hyperoxic conditions is not known.

In a recent study, Pietrofesa et al. [11] developed a novel in vivo rodent model system of combined repeated total body irradiation (IR) delivered in the form of $\gamma$-radiation and hyperoxia $\left(>95 \% \mathrm{O}_{2}\right)$ aimed to identify possible pulmonary complications associated with EVA-relevant exposures. While astronauts in reality may experience a much more complex interplay of cyclic "triple-hit" of hypobarictohyperbaric, hypoxic-to-normoxic-to-hyperoxic, and irradiation exposures the double hit radiation/hyperoxia model used in the study provided a useful hypothesis-testing model to identify potential harmful effects and to test countermeasures. The study successfully

${ }^{*}$ Corresponding author: Melpo Christofidou-Solomidou, Ph.D, Department of Medicine, Pulmonary, Allergy and Critical Care Division, University of Pennsylvania, 3615 Civic Center Boulevard, Abramson Research Building, Suite 1016C, Philadelphia, PA 19104, USA, Tel: (215)-573-9917; Fax: (215) 573-4469; E-mail: Melpo@mail.med.upenn.edu

Received September 09, 2014; Accepted November 03, 2014; Published November 07, 2014

Citation: Pietrofesa RA, Solomides CC, Christofidou-Solomidou M (2014) Flaxseed Mitigates Acute Oxidative Lung Damage in a Mouse Model of Repeated Radiation and Hyperoxia Exposure Associated with Space Exploration. J Pulm Respir Med 4: 215. doi:10.4172/2161-105X.1000215

Copyright: (c) 2014 Pietrofesa RA, et al. This is an open-access article distributed under the terms of the Creative Commons Attribution License, which permits unrestricted use, distribution, and reproduction in any medium, provided the original author and source are credited. 
Citation: Pietrofesa RA, Solomides CC, Christofidou-Solomidou M (2014) Flaxseed Mitigates Acute Oxidative Lung Damage in a Mouse Model of Repeated Radiation and Hyperoxia Exposure Associated with Space Exploration. J Pulm Respir Med 4: 215. doi:10.4172/2161105X.1000215

Page 2 of 9

identified pulmonary complications which included inflammation, fibrosis, oxidative tissue damage and apoptotic cell death.

We have shown that FS decreased radiation-induced inflammation and oxidative stress in micein different clinically-related scenarios $[12,13]$. Importantly, dietary FS mitigated thoracic radiationinduced pneumonitis and fibrosis in experimental rodent models [14]. It has been reported, that the protective effects of FS against various types of cancer such as breast [15], prostate [16], and colon cancer [17] are attributed to the presence of plant lignans. FS is the richest known source of the mammalian lignan precursor, secoisolariciresinol diglucoside (SDG). As a plant phenolic, SDG was shown in vitro to have direct hydroxyl radical scavenging properties and to inhibit lipid peroxidation [18-20]. Flaxseed lignan SDG has been reported to provide potential health benefits in several disease conditions (for review see [21]) related to hypercholesterolemia [22], diabetes [23], postmenopausal symptoms $[24,25]$, cardiovascular health [26], metabolic syndrome and bone health [27] and other diseases. Our group has performed extensive research in characterizing the beneficial effects of FS and its lignan component in experimental models of Acute Respiratory Distress Syndrome (ARDS), Ischemia-Reperfusion Injury (IRI), radiation pneumonopathy and hyperoxia $[12,13,28,29]$. In the current study, using the mouse model of combined effects of repeated exposures to hyperoxia and low-level total body radiation under controlled atmospheric conditions, we evaluated dietary administration of whole grain flaxseed (FS) as a countermeasure to the identified deleterious changes in lung tissue such as inflammation and oxidative/nitrosative damage.

\section{Materials and Methods}

\section{In vivo animal exposure study design}

Our studies used female C57/BL6 mice, a strain well characterized in our studies of both hyperoxia [30] and pulmonary radiation damage $[31,32]$. Mice were obtained from Charles River (Wilmington, MA) and irradiated at 6-8 weeks of age under animal protocols approved by the Institutional Animal Care and Use Committee (IACUC) of the University of Pennsylvania. Animals were housed in conventional cages under standardized conditions with controlled temperature and humidity and a 12-12-h day-night light cycle. Animals had free access to water and chow (Semipurified AIN-93G diet, Test Diet, Bloomsburg, IN). For this study mouse cohorts ( $\mathrm{n}=5-15$ / group) were exposed to: a) normoxia; b) $>95 \% \mathrm{O}_{2}\left(\mathrm{O}_{2}\right)$; c) $0.25 \mathrm{~Gy}$ ionizing gamma radiation (IR); or d) a combination of $>95 \% \mathrm{O}_{2}$ and $0.25 \mathrm{~Gy}$ ionizing gamma radiation $\left(\mathrm{O}_{2}+\mathrm{IR}\right)$. Mice were exposed 3 times a week for 2 weeks and sacrificed for evaluation (Figure 1).

\section{Diets and dietary treatments}

Semi-purified AIN-93G diet was used as the base diet which was supplemented with $10 \%(\mathrm{w} / \mathrm{w})$ FS as described in our previous publications [33-35]. Control and experimental diets were isocaloric and identical in physiological fuel value.

\section{Analytical evaluation of lignan content in murine plasma}

Circulating plasma levels of the flaxseed lignans ED and EL at time of sacrifice were determined by liquid chromatography/tandem mass spectrometry (LC/MS/MS) as described earlier [14,36] using commercially available standards in $95 \%$ purity (Chromadex, Inc., Santa Ana, CA). Plasma flaxseed lignan metabolite levels were evaluated in 3 randomly selected mice per cohort.

\section{Radiation Exposure of Mice}

Mouse irradiation was performed with a Gammacell 40 137Cs

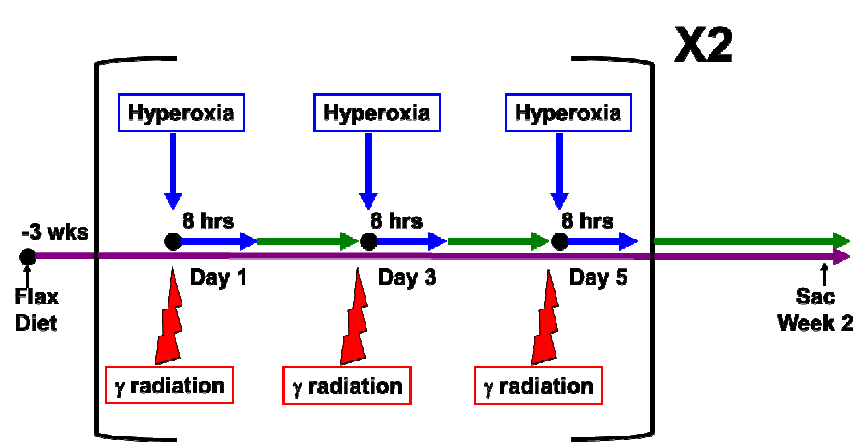

Figure 1: Experimental Plan of In Vivo Animal Exposure. Mouse cohorts ( $n=5$ / group) were fed $0 \%$ or $10 \%$ FS diet for 3 weeks prior to exposure and remained on test diets throughout the course of the study. Mice were exposed to a double-hit challenge of 0.25 Gy total body ionizing gamma irradiation (IR) and $100 \% \mathrm{pO}_{2}$ for 8 hours followed by intermittent normoxia $\left(21 \% \mathrm{pO}_{2}\right)$. This cycle was performed 3 times a week for 2 weeks. Mice were sacrificed after 2 weeks of challenge exposure. A total of 24 hours of hyperoxia/radiation exposure weekly simulates the maximum allowed weekly extravehicular activity (EVA) exposure for crewmembers on lengthy spaceflights.

irradiator (Atomic Energy of Canada Limited, Canada) as described in our previous work [11]. During irradiation, the animals were held in a circular, well-ventilated custom-made Plexiglas container that minimized their movement so that the whole body would uniformly receive the radiation dose. Mice exposed to 0 Gy served as shamcontrols.

The average dose rate was 0.43 Gy per minute and was corrected for decay each day. The delivered dose was 0.25 Gy given 3 times a week (Monday, Wednesday, and Friday). Mice were immediately placed in hyperoxic conditions for 8 hours following irradiation. The scheme on Figure 1 shows details of the in vivo procedure.

\section{Exposure of mice to hyperoxia}

Mice were exposed to a continuous flow of $\mathrm{pO}_{2}$ at $10 \mathrm{~L} / \mathrm{min}$ [11] in micro-isolator cages after removing the lids and placing the cages in a sealed Plexiglas chamber that allowed the simultaneous exposure of 6 mouse cages, yielding $\mathrm{O}_{2}$ concentrations of $95-100 \%$ [37] for 8 hours followed by intervening normoxia (ambient air containing $21 \% \mathrm{O}_{2}$ and $5 \% \mathrm{CO}_{2}$ ). This was repeated 3 times a week for 2 weeks (Figure 1).

\section{Bronchoalveolar lavage fluid analysis}

Mice were sacrificed using an overdose of ketamine $(160 \mathrm{mg} / \mathrm{Kg})$ and xylazine $(25 \mathrm{mg} / \mathrm{Kg})$ at 2 weeks from initiation of the challenge $\left(\mathrm{O}_{2}, \mathrm{IR}\right.$, or $\left.\mathrm{O}_{2}+\mathrm{IR}\right)$. Bronchoalveolar lavage (BAL) was then performed through a 20-gauge angiocatheter (BD Pharmingen, San Diego, CA), with the intra-tracheal instillation of $1 \mathrm{ml}$ of phosphate-buffered saline (PBS) containing an anti-protease cocktail (Sigma) and $5 \mathrm{mM}$ EDTA given in $0.5 \mathrm{ml}$ increments $[13,14,36]$. An aliquot was immediately separated to measure total leukocyte cell counts (cells/ml BAL fluid) using a Coulter Cell and Particle Counter (Beckman Coulter, Miami, FL). The remaining lavage fluid was centrifuged at $1,200 \mathrm{rpm}$ for 10 min and the cellfree supernatant was frozen at $-80{ }^{\circ} \mathrm{C}$ for cytokine and protein analysis.

The amount of total protein in the BAL fluid was assayed using the BCA Protein Assay Kit (Pierce, Rockford, IL) as per manufacturer's instructions. Absorbance was read at $560 \mathrm{~nm}$ (MRX Microplate Reader, Dynatech Laboratories, Chantilly, VA) and protein levels in $\mathrm{mg} / \mathrm{ml}$ of BAL fluid were calculated. The results are reported as fold change from control at week 0 . 
Citation: Pietrofesa RA, Solomides CC, Christofidou-Solomidou M (2014) Flaxseed Mitigates Acute Oxidative Lung Damage in a Mouse Model of Repeated Radiation and Hyperoxia Exposure Associated with Space Exploration. J Pulm Respir Med 4: 215. doi:10.4172/2161105X.1000215

Page 3 of 9

\section{Gene expression analysis by real-time qPCR}

Real-time quantitative Polymerase Chain Reaction (qPCR) was performed using a TaqMan ${ }^{\circ}$ Probe-Based Gene Expression Assay for transforming growth factor-beta1 (TGF-B1) supplied by Applied Biosystems, Life Technologies (Carlsbad, CA). Briefly, total RNA was isolated from lung tissue of mice fed $0 \% \mathrm{FS}$ or $10 \% \mathrm{FS}$ and exposed to challenge conditions using a commercially available kit: RNeasy Plus Mini Kit, supplied by Qiagen (Valencia, CA). Total RNA was quantified using a NanoDrop 2000 (ThermoFisher Scientific, Waltham, MA). Reverse transcription of RNA to cDNA was then performed on a Veriti Thermal Cycler using the high capacity RNA to cDNA kit supplied by Applied Biosystems, Life Technologies. qPCR was performed using 25 ng of cDNA per reaction well on a StepOnePlus ${ }^{\text {nx }}$ Real-Time PCR System (Applied Biosystems). Gene expression data was normalized to $18 \mathrm{~S}$ ribosomal RNA and was calibrated to untreated $0 \%$ FS samples according to the $\Delta \Delta \mathrm{CT}$ method.

\section{Determination of BALF TGF- $\beta$ ) and IL-1ß}

Levels of pro-inflammatory cytokines, interleukin-1 beta (IL$1 \AA)$ and tumor necrosis factor alpha (TNF- $\alpha$ ), were determined in BALF after 2 weeks of challenge exposure using enzyme-linked immunosorbent assays (ELISA). ELISA assay kits were purchased from BD biosciences (BD OptEIA Mouse TNF- $\alpha$ and IL-1ß ELISA Kit). BALF samples were run undiluted and assay was performed according to manufacturer's instructions.

\section{Determination of plasma and BALF nitrite concentration}

Levels of nitrite were determined in mouse plasma and BALF using the Greiss Reagent System supplied by Promega (Madison, WI). The Greiss Reagent System determines nitrite (a stable breakdown product of nitric oxide) concentration in biological specimens. BALF and plasma samples were run undiluted and assay was performed according to manufacturer's instructions.

\section{Tissue harvesting and evaluation of oxidative lung injury}

For histological studies, mouse lungs were instilled prior to removal from the animal with $0.75 \mathrm{ml}$ of buffered formalin through a 20 -gauge angiocatheter placed in the trachea, immersed in buffered formalin overnight and processed for conventional paraffin histology. Sections were stained withhematoxylin and eosin $(\mathrm{H} \& \mathrm{E})$ and Mason's Trichrome Blue and examined by light microscopy. Malondialdehyde (MDA), an indicator of oxidative stress [38] was measured in homogenized lung tissues using a commercially available kit (OXIS International, Portland, OR) according to manufacturer's protocol. The results were recorded as $\mu \mathrm{mol} \mathrm{MDA} / \mathrm{g}$ of lung.

Mouse plasma and BAL fluid were evaluated at 2 weeks post exposure for lipid peroxidation (an indicator of oxidative stress) using the TBARS Assay Kit (Cayman Chemical, Ann Arbor, MI, USA). Specifically, levels of thiobarbituric acid reactive substances (TBARS) were quantified by measuring the fluorescence of malondialdehydethiobarbituric acid adducts in BAL fluid samples. According to manufacturer instructions, MDA-TBA adducts were formed via acid hydrolysis at $100^{\circ} \mathrm{C}$ and measured fluorometrically with an excitation wavelength of $530 \mathrm{~nm}$ and an emission wavelength of $550 \mathrm{~nm}$. Levels of lipid peroxidation in BAL fluid are reported as the concentration $(\mu \mathrm{M})$ of MDA and in lung tissues as $\mu \mathrm{M} / \mathrm{g}$ lung tissue [11].

\section{Determination of active TGF- $\beta 1$ in bronchoalveolar lavage fluid}

Quantitative measurement of active TGF- $\beta 1$ in lung BAL fluid was performed by Enzymelinked immunosorbent assays (ELISA) according to manufacturer's recommendations (Biolegend, San Diego, CA). Specimens were run in duplicate. TGF- $\beta 1$ was expressed as $\mathrm{pg} / \mathrm{ml}$ BALF. Assay sensitivity was $2.3 \mathrm{pg} / \mathrm{mL}$ for TGF- $\beta 1$.

\section{Statistical Analysis}

Results are expressed as mean \pm SEM. Statistical differences among groups were determined using one-way analysis of variance (ANOVA) or Student's T-Test. When statistically significant differences were found $(\mathrm{p}<0.05)$ individual comparisons were made using the Bonferoni/Dunn test (Statview 4.0).

\section{Results}

Challenges associated with space travel, whether hyperoxia [30] or radiation [39], induce architectural lung tissue changes and lung oxidative tissue damage [11]. We have previously developed a murine model that permits the study of the combination of the two challenges and in the current study we determined the usefulness of wholegrain FS in preventing the lung damaging effects associated with such exposures. Mice were fed $0 \%$ or $10 \%$ FS and exposed to short-duration hyperoxia (8 hours), low-level irradiation ( $0.25 \mathrm{~Gy})$, or the combination of both challenges. We evaluated the usefulness of wholegrain FS in this murine model system after 2 weeks of challenge exposure as we have previously observed significant acute lung injury and inflammation (Figure 1).

Detection of the mammalian lignans, enterodiol and enterolactone, in mice fed wholegrain flaxseed

Wholegrain FS is an abundant source of the plant lignan secoisolariciresinol diglucoside (SDG). Following ingestion, SDG is converted by intestinal bacteria to the mammalian lignin enterodiol (ED) and enterolactone (EL), which then enter the circulation and can be detected in plasma. Mice were pre-fed $0 \%$ or $10 \%$ FS for 3 weeks prior to challenge exposure and for the duration of challenge exposure. After 2 weeks of exposure, we determined plasma levels of ED (Figure $2 \mathrm{~A}$ ) and ED (Figure 2B). We detected significantly high plasma levels of the mammalian lignans in all mouse cohorts fed $10 \%$ FS. Levels of $\mathrm{ED}$ and EL were below the lower limit of detection in plasma from all mouse cohorts fed 0\% FS. Compared to untreated mice fed $10 \%$ FS $(E D=1991.1 \mathrm{nM} ; \mathrm{EL}=536.3 \mathrm{nM})$, mouse cohorts exposed to $\mathrm{O}_{2}$, IR, and $\mathrm{O}_{2}+\mathrm{IR}$ displayed plasma enterodiol levels ranging from 58.9-1066.21 $\mathrm{nM}$ and plasma enterolactone levels ranging from 118.21-583.4 nM. We observed no significant changes in mouse bodyweight after 2 weeks of challenge exposure (data not shown).

Lung inflammation associated with exposure to repeated cycles of hyperoxia, low-level total body radiation and combination challenge is improved by wholegrain flaxseed

Pulmonary inflammation is routinely evaluated by determining inflammatory cell influx inthe BAL fluid. After 2 weeks of exposure, mice fed $0 \%$ FS has significant lung inflammation as determined by PMN cell counts in bronchoalveolar lavage fluid (BALF). While no PMN cells were detected in untreated mice fed $0 \%$ FS, all challenges induced significant PMN influx $(\mathrm{p}<0.05)$ in mice fed $0 \%$ FS $(968,1401$, and 467 PMN cells per $\mathrm{ml}$ BALF for $\mathrm{O}_{2}$, IR, and $\mathrm{O}_{2}+\mathrm{IR}$ respectively) (Figure 3A). Notably, PMN cells were entirely absent in BALF from mice fed $10 \%$ FS. Alternatively, no significant differences were determined in the total number of white blood cells in BALF and in BALF protein levels across all study cohorts (data not shown).

The inflammatory response was further characterized by determining the levels of proinflammatory cytokines, interleukin-1 beta (IL-1ß) and tumor necrosis factor alpha (TNF- $\alpha$ ), in BALF after 
Citation: Pietrofesa RA, Solomides CC, Christofidou-Solomidou M (2014) Flaxseed Mitigates Acute Oxidative Lung Damage in a Mouse Model of Repeated Radiation and Hyperoxia Exposure Associated with Space Exploration. J Pulm Respir Med 4: 215. doi:10.4172/2161105X.1000215

Page 4 of 9
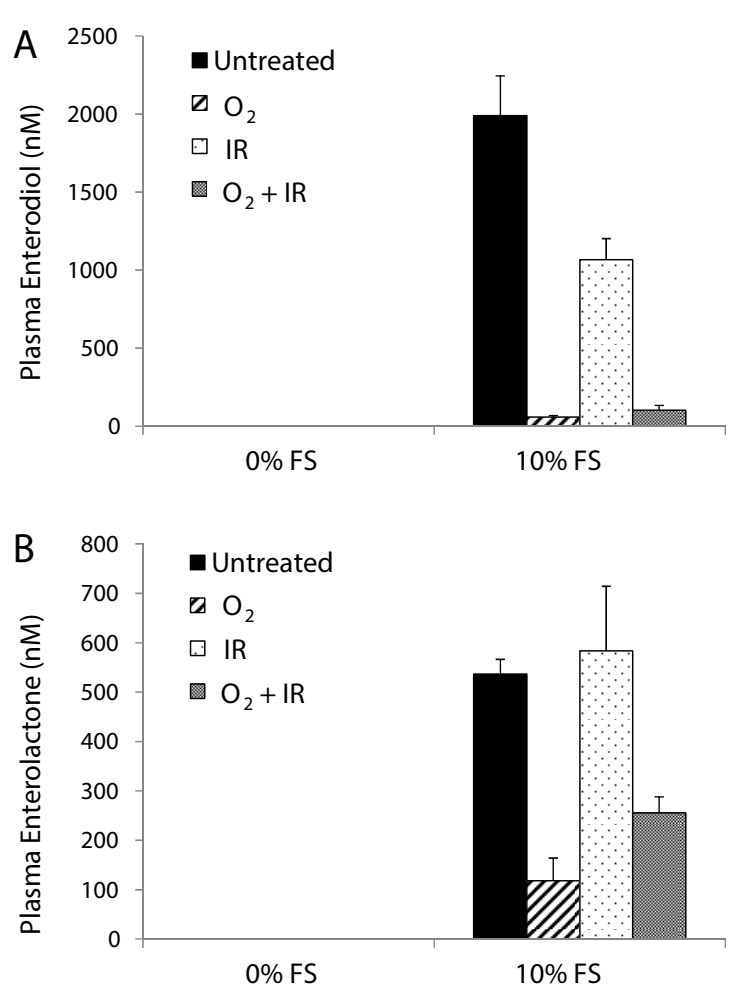

Figure 2: Detection of Mammalian Lignans in Mouse Plasma. Separate cohorts of mice ( $n=5 /$ group) were fed $0 \%$ or $10 \%$ FS diet and exposed to $100 \% \mathrm{O}_{2}$ for 8 hours only $\left(\mathrm{O}_{2}\right), 0.25$ Gy total body ionizing gamma irradiation (IR) only, or a double-hit combination of both challenges $\left(\mathrm{O}_{2}+\mathrm{IR}\right)$ followed by intermitten normoxia $\left(21 \% \mathrm{pO}_{2}\right)$ for repeated cycles 3 times a week for 2 weeks. Mice were sacrificed after 2 weeks of challenge exposure and plasma analyzed for levels of circulating mammalian lignans enterodiol (Panel A) and enterolactone (Panel B) using GC/MS/MS. Data is represented as mean \pm SEM.
2 weeks of challenge exposure using enzyme-linked immunosorbent assays (ELISA). Exposure to challenge conditions led to significant increases $(\mathrm{p}<0.05)$ in the levels of IL-1ß in mice fed $0 \%$ FS (Figure 3B). $10 \%$ FS significantly reduced levels of IL- $1 ß$ by 39,47 , and $66 \%$ in cohorts exposed to $\mathrm{O}_{2}, \mathrm{IR}$, and $\mathrm{O}_{2}+\mathrm{IR}$ respectively. Similarly, elevated levels of BALF TNF- $\alpha$ in mouse cohorts fed $0 \%$ FS and exposed to all challenge conditions were significantly $(\mathrm{p}<0.05)$ blunted by $10 \%$ FS $(77$, 78 , and $96 \%$ reduction in $10 \%$ FS fed mice exposed to $\mathrm{O}_{2}$, IR, and $\mathrm{O}_{2}+\mathrm{IR}$ respectively, compared to mouse cohorts fed 0\% FS) (Figure 3C).

\section{Flaxseed reduces hyperoxia and radiation induced oxidative stress in murine lung tissue}

Oxidative tissue damage relevant to spaceflight has been identified and confirmed recently in both lipids and DNA [40]. Specifically, lipid peroxidation plays a major role in mediating oxidativedamage in tissues, is a qualitative indicator of oxidative stress within tissues and cells, and can be measured by determining the amount of malondialdehyde (MDA), a product of lipid peroxidation in lung tissues [14,36]. In the current study, we determined significant $(\mathrm{p}<0.05)$ increases in MDA concentration in both lung tissue (Figure $4 \mathrm{~A}$ ) and BALF (Figure $4 \mathrm{~B}$ ) of mice fed $0 \% \mathrm{FS}$ and exposed to all challenge conditions. Additionally, we determined no significant increase in lung tissue MDA concentration over untreated control in mice fed $10 \% \mathrm{FS}$ and exposed to $\mathrm{O}_{2}$ or $\mathrm{O}_{2}+\mathrm{IR}$. Furthermore, BALF MDA concentrations were significantly reduced by 52,43 , and $37 \%$ in mice fed $10 \%$ FS and exposed $\mathrm{O}_{2}, \mathrm{IR}$, and $\mathrm{O}_{2}+\mathrm{IR}$, respectively, relative to $0 \% \mathrm{FS}$ fed mouse cohorts.

Hyperoxia, low-level total body radiation and double-hit combination challenge induce acute elevations in nitrosative stress that is improved by wholegrain flaxseed

We further explored the significant elevation in oxidative stress and oxidative tissue damage observed in mouse cohorts exposed to challenge conditions by determining the presence of nitrosative stress in both BALF and plasma. Acting along with reactive oxygen species,
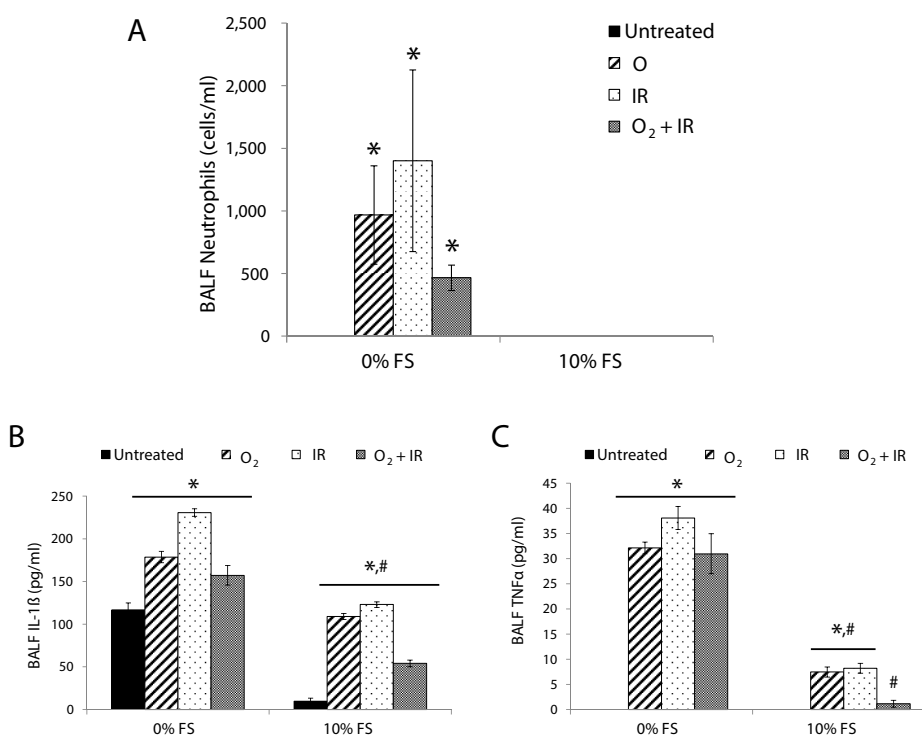

Figure 3: Flaxseed ameliorates increased Hyperoxia, Radiation, or Double-Hit Combination Challenge Induced Lung Inflammation and Proinflammatory Cytokine Release. Separate cohorts of mice ( $n=5 /$ group) were fed $0 \%$ or $10 \% \mathrm{FS}$ diet and exposed to $100 \% \mathrm{O}_{2}$ for 8 hours only $\left(\mathrm{O}_{2}\right)$, $0.25 \mathrm{~Gy}$ total body ionizing gamma irradiation (IR) only, or a double-hit combination of both challenges $\left(\mathrm{O}_{2}+\mathrm{IR}\right)$ followed by intermittent normoxia $\left.(21 \% \text { pO })_{2}\right)$ for repeated cycles 3 times a week for 2 weeks. Mice were sacrificed after 2 weeks of challenge exposure. BALF was evaluated for total neutrophil cell counts (Panel A) and levels of pro-inflammatory cytokines, IL-1ß (Panel B) and TNFa (Panel C). Data is represented as mean \pm SEM. ${ }^{*} \mathrm{p}<0.05$ for $\mathrm{O}_{2}$, IR, and $\mathrm{O}_{2}+\mathrm{IR}$ versus respective untreated control mice in each diet cohort. \#p $<0.05$ for respective $0 \% \mathrm{FS}$ fed mice exposed to $\mathrm{O}_{2}$, IR, and $\mathrm{O}_{2}+\mathrm{IR}$ versus $10 \% \mathrm{FS}$ fed mice exposed to $\mathrm{O}_{2}$, IR, and $\mathrm{O}_{2}+\mathrm{IR}$. 
Citation: Pietrofesa RA, Solomides CC, Christofidou-Solomidou M (2014) Flaxseed Mitigates Acute Oxidative Lung Damage in a Mouse Model of Repeated Radiation and Hyperoxia Exposure Associated with Space Exploration. J Pulm Respir Med 4: 215. doi:10.4172/2161105X.1000215

reactive nitrogen species are generated upon the reaction of nitric oxide and superoxide. In the current study, we determined the levels of BALF and plasma nitrite, which is a stable and measurable breakdown product of nitric oxide. BALF nitrite was significantly $(\mathrm{p}<0.01)$ elevated $10.7,8.8$, and 9.5 fold over untreated in mouse cohorts fed $10 \%$ FS and exposed to $\mathrm{O}_{2}$, IR, and $\mathrm{O}_{2}+\mathrm{IR}$, respectively (Figure 5A). Additionally, $0 \%$ FS fed mice exposed to hyperoxia only displayed a significant $(\mathrm{p}<0.05)$ elevation in plasma nitrite concentration (Figure 5B). Levels of BALF and plasma nitrite were significantly $(\mathrm{p}<0.05)$ reduced in mouse cohorts exposed to all challenge conditions and fed 10\% FS.

Acute fibrotic lung changes in mice exposed to repeated cycles of hyperoxia, low-level total body radiation and double-hit combination challenge are mitigated by flaxseed

Single or fractionated exposure of lung tissues to ionizing radiation [41] as well as to high oxygen levels [42] is associated with excess deposition of extracellular collagen fibers implicated in fibrotic lung changes. We have previously determined pulmonary fibrosis resulting from repeated lowlevel radiation challenge, in combination with hyperoxic exposure that was associated with acute elevations in BALF levels of active TGF- $\beta 1$, a pro-fibrogenic cytokine. To first test this, we evaluated the total hydroxyproline content of murine lungs after 2
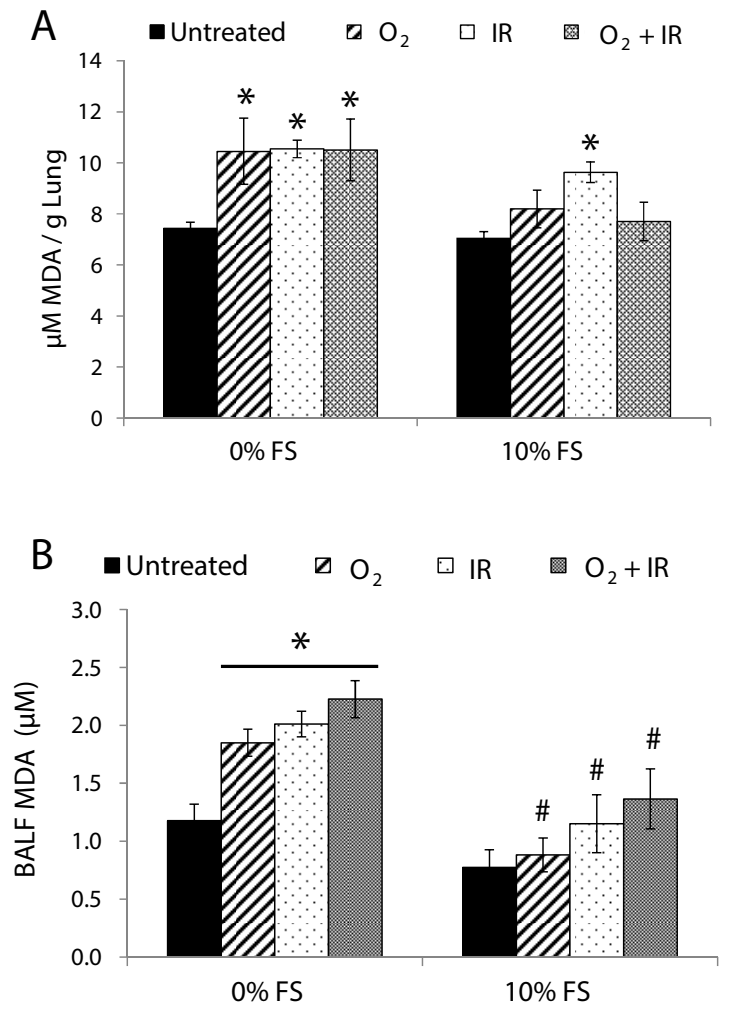

Figure 4: Flaxseed mitigates increased Oxidative Stress in Lung Tissue and BALF due to Hyperoxia, Radiation, or Double-Hit Combination Challenge Separate cohorts of mice ( $n=5 /$ group) were fed $0 \%$ or $10 \%$ FS diet and exposed to $100 \% \mathrm{O}_{2}$ for 8 hours only $\left(\mathrm{O}_{2}\right), 0.25 \mathrm{~Gy}$ total body ionizing gamma irradiation (IR) only, or a double-hit combination of both challenges $\left(\mathrm{O}_{2}+\mathrm{IR}\right)$ followed by intermittent normoxia $\left(21 \% \mathrm{pO}_{2}\right)$ for repeated cycles 3 times a week for 2 weeks. Mice were sacrificed after 2 weeks of challenge exposure. Levels of malondialdehyde, a marker of lipid peroxidation, were determined in mouse lung tissue (Panel A) and BALF (Panel B). Data is represented as mean \pm SEM. ${ }^{*} \mathrm{p}<0.05$ for $\mathrm{O}_{2}, \mathrm{IR}$, and $\mathrm{O}_{2}+\mathrm{IR}$ versus respective untreated control mice in each diet cohort. $\# p<0.05$ for $0 \%$ FS fed mice exposed to $\mathrm{O}_{2}, I R$, and $\mathrm{O}_{2}+\mathrm{IR}$ versus respective $10 \% \mathrm{FS}$ fed mice exposed to $\mathrm{O}_{2}$, IR, and $\mathrm{O}_{2}+\mathrm{IR}$.
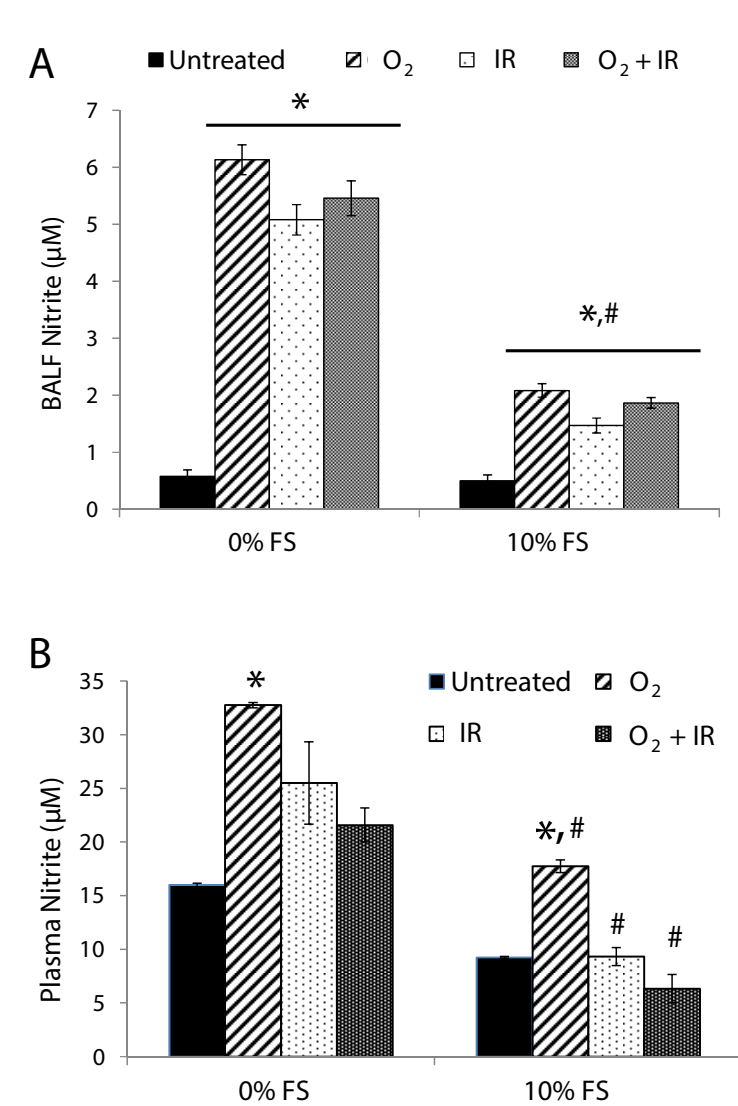

Figure 5: Flaxseed Abrogates increased Nitrosative Stress from Exposure to Hyperoxia, Radiation, or Double-Hit Combination Challenge Separate cohorts of mice ( $n=5 /$ group) were fed $0 \%$ or $10 \%$ FS diet and exposed to $100 \% \mathrm{O}_{2}$ for 8 hours only $\left(\mathrm{O}_{2}\right), 0.25$ Gy total body ionizing gamma irradiation (IR) only, or a double-hit combination of both challenges $\left(\mathrm{O}_{2}+\mathrm{IR}\right)$ followed by intermittent normoxia $\left(21 \% \mathrm{pO}_{2}\right)$ for repeated cycles 3 times a week for 2 weeks. Mice were sacrificed after 2 weeks of challenge exposure. Levels of nitrite, a stable breakdown product of nitric oxide, were determined in mouse BALF (Panel A) and plasma (Panel B). Data is represented as mean \pm SEM. ${ }^{*} p<0.05$ for $\mathrm{O}_{2}, I R$, and $\mathrm{O}+\mathrm{IR}$ versus respective untreated control mice in each diet cohort. \#p< 0.05 for $0 \% \mathrm{FS}$ fed mice exposed to $\mathrm{O}_{2}, \mathrm{IR}$, and $\mathrm{O}_{2}+\mathrm{IR}$ versus respective $10 \%$ FS fed mice exposed to $\mathrm{O}_{2}$, IR, and $\mathrm{O}_{2}+\mathrm{IR}$.

weeks of challenge exposure (Figure 6A). Analysis of hydroxyproline content in the lung is a quantitative measure of irreversible collagen deposition and fibrosis, which is expressed as $\mu \mathrm{g}$ of hydroxyproline/ lung. Untreated mice fed $0 \%$ FS had hydroxyproline levels equivalent to $73.2 \mu \mathrm{g} / \mathrm{g}$ of lung tissue. Mice exposed to $\mathrm{O}_{2}$, IR, and $\mathrm{O}_{2}+\mathrm{IR}$ had significantly $(\mathrm{p}<0.05)$ increased levels of hydroxyproline equal to 92.6 , 116.1 , and $114.8 \mu \mathrm{g} / \mathrm{g}$ of lung tissue; a $26.5,58.6$, and $56.9 \%$ increase from control. Alternatively, levels of hydroxyproline in mouse cohorts fed $10 \%$ FS were significantly lower than the respective mouse cohorts fed $0 \%$ FS. Compared to the average level of hydroxyproline $(54.7 \mu \mathrm{g} / \mathrm{g}$ of lung) in untreated mice fed $10 \% \mathrm{FS}$, mouse cohorts exposed to $\mathrm{O}_{2}$, $\mathrm{IR}$, and $\mathrm{O}_{2}+\mathrm{IR}$ had comparable levels of hydroxyproline equal to 56.7 , 69.5 , and $56.3 \mu \mathrm{g} / \mathrm{g}$ of lung tissue.

We explored this observation of increased collagen deposition in lung tissue by evaluating lungspecific mRNA changes in transforming growth factor-betal (TGF-ß1), which is a key activator of tissue repair and the synthesis of extracellular matrix proteins (Figure 6B). We determined a significant $(\mathrm{p}<0.05)$ 1.61- and 1.55-fold induction of TGF- $ß 1$ over control in mice fed $0 \%$ FS and exposed to hyperoxia or radiation, respectively. Notably, the double-hit challenge of hyperoxia 
Citation: Pietrofesa RA, Solomides CC, Christofidou-Solomidou M (2014) Flaxseed Mitigates Acute Oxidative Lung Damage in a Mouse Model of Repeated Radiation and Hyperoxia Exposure Associated with Space Exploration. J Pulm Respir Med 4: 215. doi:10.4172/2161105X.1000215

and radiation exposure further induced mRNA levels of TGF- 312.55 fold higher, relative to control. These elevations in lung mRNA levels of TGF- $ß 1$ from mice exposed to challenge conditions and fed $0 \%$ FS were absent from mice fed $10 \%$ FS.

To determine whether the detected fibrotic changes and increased TGF-ß1 mRNA content in lung tissue are associated with secretion

A

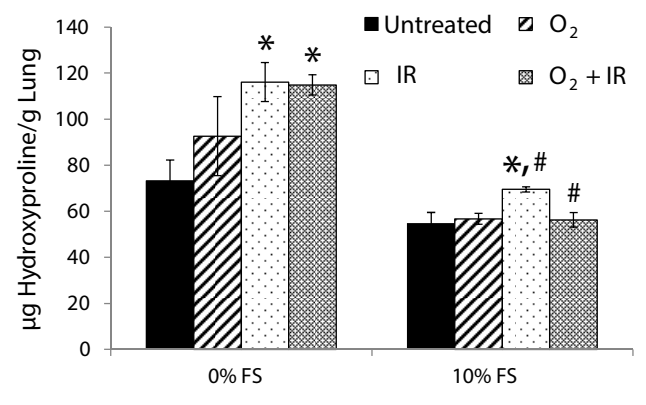

B

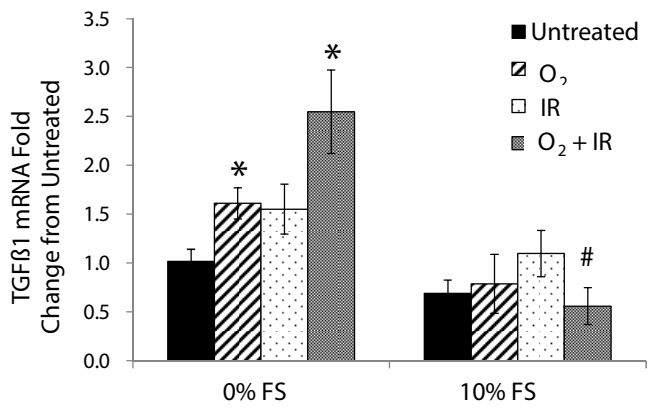

C

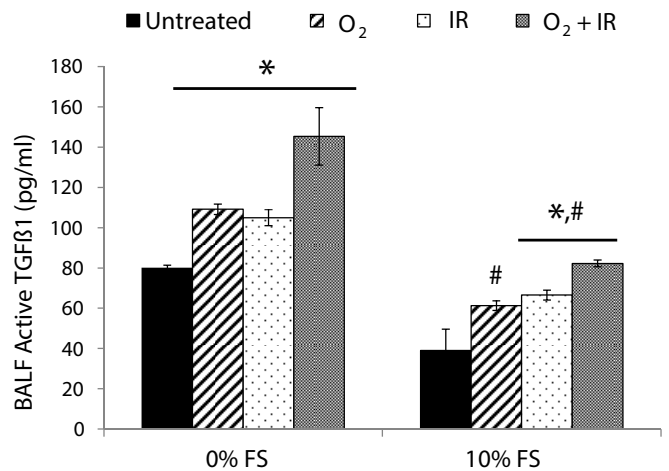

Figure 6: Flaxseed blunts increased Lung Fibrosis and Profibrogenic Cytokine Levels induced by Exposure to Hyperoxia, Radiation, or DoubleHit Combination Challenge Separate cohorts of mice ( $n=5 /$ group) were fed $0 \%$ or $10 \%$ FS diet and exposed to $100 \% \mathrm{O}_{2}$ for 8 hours only $\left(\mathrm{O}_{2}\right), 0.25$ Gy total body ionizing gamma irradiation (IR) only, or a double-hit combination of both challenges $\left(\mathrm{O}_{2}+\mathrm{IR}\right)$ followed by intermittent normoxia $\left(21 \% \mathrm{pO}_{2}\right)$ for repeated cycles 3 times a week for 2 weeks. Mice were sacrificed after 2 weeks of challenge exposure. Lung tissue was harvested and evaluated for hydroxyproline content, a measure of fibrosis (Panel A). Changes in lung tissue mRNA levels of profibrogenic TGFß1 were determined quantitative realtime PCR analysis (Panel B). Analysis was performed in duplicate and gene expression normalized to 18S ribosomal RNA. Levels of active TGFß1 were determined in mouse BALF using ELISA (Panel C). All data is represented as mean \pm SEM. ${ }^{*} \mathrm{p}<0.05$ for $\mathrm{O}_{2}, I R$, and $\mathrm{O}_{2}+\mathrm{IR}$ versus respective untreated control mice in each diet cohort. $\# p<0.05$ for $0 \% \mathrm{FS}$ fed mice exposed to $\mathrm{O}_{2}$, IR, and $\mathrm{O}_{2}+\mathrm{IR}$ versus respective $10 \% \mathrm{FS}$ fed mice exposed to $\mathrm{O}_{2}, \mathrm{IR}$, and $\mathrm{O}_{2}+\mathrm{IR}$.
0\% FLAXSEED
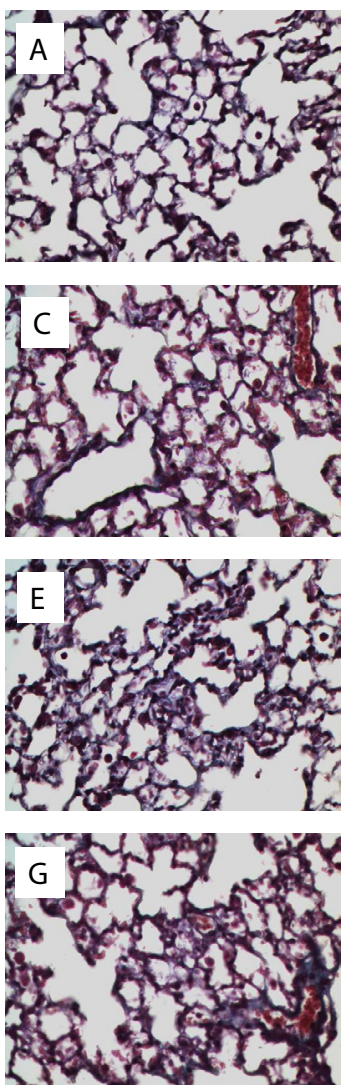
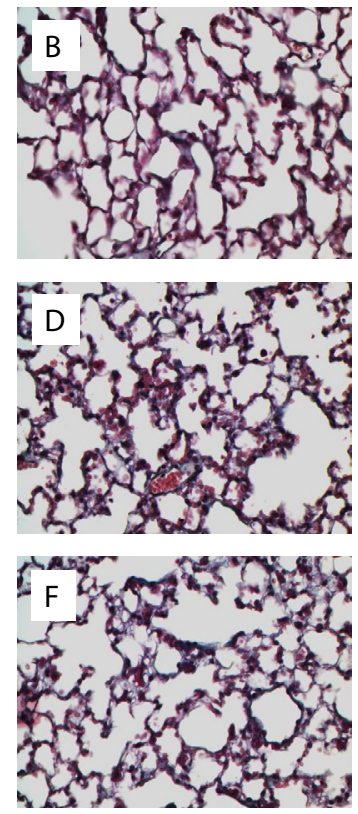

$\mathrm{O}_{2}+\mathrm{IR}$

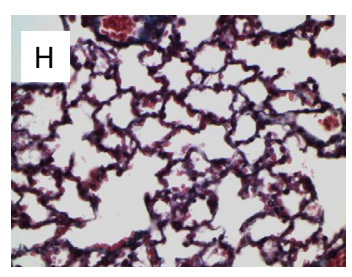

$10 \%$ FLAXSEED

Figure 7: Flaxseed blunts increased Lung Fibrosis induced by Exposure to Hyperoxia, Radiation, or Double-Hit Combination Challenge-A histological evaluation Representative lung photomicrographs are shown here, from the mouse cohorts described in Figure 6. Sections are stained with Mason's Trichrome Blue to identify collagen deposition. Magnification, 400X.

of the pro-fibrogenic cytokines, the levels of active TGF- $\beta 1$ were determined in the BALF of mice at using ELISA (Figure 6C). Significant elevations $(p<0.05)$ in active TGF- $\beta 1$ was detected in all cohorts fed $0 \%$ FS and exposed to $\mathrm{O}_{2}$, IR, or $\mathrm{O}_{2}+\mathrm{IR}$ as compared to untreated controls. Levels were significantly $(\mathrm{p}<0.05)$ reduced across all mouse cohorts fed $10 \%$ FS. Notably, the levels of BALF active TGF- $B 1$ were comparable to the level determined in untreated $0 \% \mathrm{FS}$ fed mice and confirm previous findings relating to fibrotic changes and TGF- $\$ 1 \mathrm{mRNA}$ induction in lung tissues of $0 \%$ FS fed mice. using Mason's Trichrome Blue staining (Figure 7) displays a mild increase in collagen deposition (blue color) in mouse cohorts fed $0 \% \mathrm{FS}$ and exposed to $\mathrm{O}_{2}$, IR, and $\mathrm{O}_{2}+\mathrm{IR}$ (Panels $\mathrm{C}, \mathrm{E}$, and $\mathrm{G}$ ) as compared to $10 \%$ FS-fed mice (Panels D, F, and H). This corroborates the hydroxyproline findings (Figure 6A).

\section{Discussion}

Using a novel in vivo system of combined repeated exposure to low-level total body $\gamma$-irradiation and hyperoxia, as a simplified model of a pre-breathe protocol that crewmembers may be subjected prior to an EVA, our group identified oxidative lung damage associated with systemic effects [11]. We demonstrated a significant impairment of blood oxygenation and systemic oxidative stress, related to repeated radiation and hyperoxia exposure as well as increased pulmonary inflammation and bronchoalveolar lavage protein levels indicating the development of significant lung tissue injury. In the current study, we 
Citation: Pietrofesa RA, Solomides CC, Christofidou-Solomidou M (2014) Flaxseed Mitigates Acute Oxidative Lung Damage in a Mouse Model of Repeated Radiation and Hyperoxia Exposure Associated with Space Exploration. J Pulm Respir Med 4: 215. doi:10.4172/2161105X.1000215

Page 7 of 9

used the same model to evaluate dietary administration of wholegrain flaxseed, a grain with potent antioxidant, anti-inflammatory and antifibrotic properties, shown by our group to be protective in lung tissues $[12-14,34,43]$. We report here for the first time that in a novel model of repeat hyperoxia and radiation exposure, flaxseed intake mitigated adverse effects in lung, thus proving to be a promising countermeasure to potential health risks associated with space exploration.

Data collected by NASA suggest that lung cancer is a major risk for space travel mainly due to space radiation exposure [44,45]. While focus thus far has been on cancer development in lung post exposure to space radiation, important risks to lung function and tissue pathophysiology have been poorly studied and understood. Our study aimed to close the knowledge gap by identifying acute tissue degenerative processes that might lead to impaired lung function long before cancer develops. In addition, we aimed to abrogate this degenerative process by evaluating a potential countermeasure that has shown efficacy in hyperoxic and radiation exposure of lung tissues.

Several nutritional approaches have been suggested as countermeasures to space travel-related pathologies. A nutritional nucleotide supplement has been proposed for ameliorating microgravity induced impairment of the immune system [46] while selenomethionine [47,48], a known antioxidant, was proposed to ameliorate radiation toxicity. Nutritional antioxidant cocktails have also been shown to be radioprotective of hematopoietic cells and even boost animal survival [49] in mice exposed to spacerelevant radiation such as protons and gamma radiation. Wholegrain flaxseed (FS) and its bioactive metabolic components have been extensively studied in other organ systems and have proven to be beneficial, mostly in regards to cancer including breast [50], colon [51,52], ovarian [53,54] or prostate [55] cancer. Our group was the first to show that dietary FS supplementation could also reduce lung inflammation and lipid peroxidation in murine models of acid aspiration and hyperoxia [12] and more recently, in lung ischemia/ reperfusion injury related to transplantation damage [13]. Our group pioneered the studies establishing the radioprotective and radiation mitigating properties in lung of FS and FS lignan component [14,3335,43]. Evaluating the usefulness of this nutritional agent in blunting adverse effects in lung by the cycling and combinatorial effects of hyperoxia and radiation exposures is novel as this agent has never been tested as countermeasure relevant to space travel complications.

The information presented here by our group is quite unique and applicable to ongoing research in human space missions. Importantly, while prior studies [30] have characterized the effects where by hyperoxia alone or radiation alone affects pulmonary tissues, no previous research has investigated the role of a) both exposures (double-hit), b) repeated insults (cycling hyperoxia/normoxia) or c) evaluated countermeasures to the tissue damage resulting from such exposures. Additionally, models designed to test such complex interactions on a tissue and cellular/molecular level are unique to our approach. Research in the field of space travel and changes in the anatomy, physiology, and genome of animal tissues is limited and thus, its planned application to the propagation of manned space travel is unique and appealing. Our data show that a number of markers of acute radiation effects are altered by FS. One such marker is the level of TGF- $\beta 1$ expression. Indeed, TGF- $\beta 1$ mRNA levels have been demonstrated to surge soon after irradiation and that this elevation is reversible with a single dose of radioprotective antioxidant enzymes (AOEs) administered intravenously [56,57]. The results from the current study are consistent with this previous data in that creating an antioxidant-rich environment by FS feeding at the time of radiation (and or hyperoxia) exposure that abrogates the early rise in the proliferative cytokine TGF- $\beta 1$.
During the acute phase of radiation-, hyperoxia- and the combination treatment-induced lung injury, FS inhibited oxidative and nitrosative stress as well as inflammatory cell influx. Studies by Lee at al. [13] showed that inflammatory cells isolated from lung lavage of FSfed animals are inhibited in respiratory burst and ROS release when stimulated. In addition, a decrease in the release of TNF-a and IL1b pro-inflammatory cytokine by FS shown in this study, may help explain the combinatorial antioxidant/anti-inflammatory, protective effects of FS as an effective countermeasure in this injury model. Nitrosative stress is a hallmark of both radiation and hyperoxic [58] lung damage. Protective effects of FS in irradiated lung tissues have been associated with inhibition of nitrotyrosine formation [35].

\section{Conclusion}

In summary, this study evaluates a non-toxic, widely available nutritional supplement that offers long term tissue radioprotective effects in the setting of repeated cycles of total body radiation and hyperoxia exposure associated with an EVA. Potential mechanisms of the effects of prolonged FS feeding include altering immediate radiation- and hyperoxia-induced markers of lung damage, creating a baseline tissue-protective state prior to exposure, and providing high levels of circulating antioxidants from the continued metabolism is of bioactive flaxseed lignans. We have identified a novel countermeasure agent to the pulmonary complications from space travel which could include inflammation, fibrosis, and oxidative tissue damage. In conclusion, we have identified flaxseed as a promising protective agent for adverse effects associated with prolonged space travel using a novel murine model of double-hit repeated low-level radiation and hyperoxia exposure.

\section{Authors' contributions}

RAP performed animal experiments, biochemical tissue assays and conducted data analysis. CCS performed pathology assessment of histological specimens. MCS designed the study and individual experiments, analyzed data, wrote the manuscript and supervised lab personnel.

\section{Acknowledgements and Funding}

The authors wish to thank Ms. Evguenia Arguiri for her technical support. This work was funded in part by: By the NASA Human Research Program through a NASA-NIH Interagency Agreement for supplemental award to NIH and by NASA award \#NNX12AK19G (MCS), NCI 5R01C 133470 (MCS), NIH-RC1AI081251 (MCS), 1R03CA180548 (MCS) and by pilot project support from 1P30 ES013508 02 awarded to MCS (its contents are solely the responsibility of the authors and do not necessarily represent the official views of the NIEHS, NIH).

\section{References}

1. Prisk GK (2005) The lung in space. Clin Chest Med 26: 415-438, vi.

2. Hu S, Kim MH, McClellan GE, Cucinotta FA (2009) Modeling the acute health effects of astronauts from exposure to large solar particle events. Health Phys 96: $465-476$.

3. Townsend LW (2005) Implications of the space radiation environment for human exploration in deep space. Radiat Prot Dosimetry 115: 44-50.

4. Holloway RJ, Leong GF, Ainsworth EJ, Albright ML, Baum SJ (1967) Recovery from radiation injury in the hamster as evaluated by the split-dose technique. USNRDL-TR-1111. Res Dev Tech Rep

5. Leong GF, Page NP, Ainsworth EJ, Hanks GE (1966) Injury accumulation in sheep during protracted gamma radiation. USNRDL-TR-998. Res Dev Tech Rep .

6. Reitz G, Berger T (2006) The MATROSHKA facility--dose determination during an EVA. Radiat Prot Dosimetry 120: 442-445.

7. Berger T, Bilski P, Hajek M, Puchalska M, Reitz G (2013) The MATROSHKA experiment: results and comparison from extravehicular activity (MTR-1) and intravehicular activity (MTR-2A/2B) exposure. Radiat Res 180: 622-637.

8. Larkin EC, Adams JD, Williams WT, Duncan DM (1972) Hematologic responses to hypobaric hyperoxia. Am J Physiol 223: 431-437. 
Citation: Pietrofesa RA, Solomides CC, Christofidou-Solomidou M (2014) Flaxseed Mitigates Acute Oxidative Lung Damage in a Mouse Model of Repeated Radiation and Hyperoxia Exposure Associated with Space Exploration. J Pulm Respir Med 4: 215. doi:10.4172/2161105X.1000215

Page 8 of

9. Hellweg CE, Baumstark-Khan C (2007) Getting ready for the manned mission to Mars: the astronauts' risk from space radiation. Naturwissenschaften 94 : 517-526

10. Cucinotta FA, Kim MH, Willingham V, George KA (2008) Physical and biological organ dosimetry analysis for international space station astronauts. Radiat Res 170: $127-138$.

11. Pietrofesa RA, Turowski JB, Arguiri E, Milovanova TN, Solomides CC, et al. (2013) Oxidative Lung Damage Resulting from Repeated Exposure to Radiation and Hyperoxia Associated with Space Exploration. J Pulm Respir Med 3: 5.

12. Kinniry P, Amrani Y, Vachani A, Solomides CC, Arguiri E, et al. (2006) Dietary flaxseed supplementation ameliorates inflammation and oxidative tissue damage in experimental models of acute lung injury in mice. J Nutr 136, 15451551.

13. Lee JC, Bhora F, Sun J, Cheng G, Arguiri E, et al. (2008) Dietary flaxseed enhances antioxidant defenses and is protective in a mouse model of lung ischemia-reperfusion injury. Am J Physiol Lung Cell Mol Physiol 294: L255-265.

14. Lee JC, Krochak R, Blouin A, Kanterakis S, Chatterjee S, et al. (2009) Dietary flaxseed prevents radiation-induced oxidative lung damage, inflammation and fibrosis in a mouse model of thoracic radiation injury. Cancer Biol Ther 8: 47-53.

15. Chen H, Sun B, Pan S, Jiang H, Sun X (2009) Dihydroartemisinin inhibits growth of pancreatic cancer cells in vitro and in vivo. Anticancer Drugs 20 : $131-140$.

16. Demark-Wahnefried W, Polascik TJ, George SL, Switzer BR, Madden JF, et al (2008). Flaxseed supplementation (not dietary fat restriction) reduces prostate cancer proliferation rates in men presurgery. Cancer Epidemiol Biomarkers Prev 17: 3577-3587.

17. Jenab M, Thompson LU (1996) The influence of flaxseed and lignans on colon carcinogenesis and beta-glucuronidase activity. Carcinogenesis 17: 13431348.

18. Prasad K (1997) Hydroxyl radical-scavenging property of secoisolariciresino diglucoside (SDG) isolated from flax-seed. Mol Cell Biochem 168: 117-123.

19. Prasad K (2000) Antioxidant Activity of Secoisolariciresinol Diglucoside-derived Metabolites, Secoisolariciresinol, Enterodiol, and Enterolactone. Int J Angiol 9 : 220-225.

20. Kitts DD, Yuan YV, Wijewickreme AN, Thompson LU (1999) Antioxidant activity of the flaxseed lignan secoisolariciresinol diglycoside and its mammalian lignan metabolites enterodiol and enterolactone. Mol Cell Biochem 202: 91-100.

21. Adolphe JL, Whiting SJ, Juurlink BH, Thorpe LU, Alcorn J (2010) Health effects with consumption of the flax lignan secoisolariciresinol diglucoside. $\mathrm{Br} \mathrm{J}$ Nutr 103: 929-938.

22. Fukumitsu S, Aida K, Shimizu H, Toyoda K (2010) Flaxseed lignan lowers blood cholesterol and decreases liver disease risk factors in moderately hypercholesterolemic men. Nutr Res 30: 441-446.

23. Pan A, Demark-Wahnefried W, Ye X, Yu Z, Li H, et al. (2009) Effects of a flaxseed-derived lignan supplement on C-reactive protein, IL-6 and retinolbinding protein 4 in type 2 diabetic patients. Br J Nutr 101: 1145-1149.

24. Hallund J, Tetens I, Bugel S, Tholstrup T, Bruun JM (2008) The effect of a lignin complex isolated from flaxseed on inflammation markers in healthy postmenopausal women. Nutrition, metabolism, and cardiovascular disease NMCD 18: 497-502.

25. Hallund J, Tetens I, Bügel S, Tholstrup T, Ferrari M, et al. (2006) Daily consumption for six weeks of a lignan complex isolated from flaxseed does not affect endothelial function in healthy postmenopausal women. J Nutr 136 2314-2318.

26. Jenkins DJ, Kendall CW, Vidgen E, Agarwal S, Rao AV, et al. (1999) Health aspects of partially defatted flaxseed, including effects on serum lipids, oxidative measures, and ex vivo androgen and progestin activity: a controlled crossover trial. Am J Clin Nutr 69, 395-402.

27. Cornish SM, Chilibeck PD, Paus-Jennsen L, Biem HJ, Khozani T, et al. (2009) A randomized controlled trial of the effects of flaxseed lignan complex on metabolic syndrome composite score and bone mineral in older adults. Appl Physiol Nutr Metab 34: 89-98.

28. Metnitz PG, Bartens C, Fischer M, Fridrich P, Steltzer H, et al. (1999) Antioxidant status in patients with acute respiratory distress syndrome. Intensive Care Med 25: $180-185$

29. Prasad K (1997) Dietary flax seed in prevention of hypercholesterolemic atherosclerosis. Atherosclerosis 132: 69-76.
30. Perkowski S, Scherpereel A, Murciano JC, Arguiri E, Solomides CC, et al. (2006) Dissociation between alveolar transmigration of neutrophils and lung injury in hyperoxia. Am J Physiol Lung Cell Mol Physiol 291: L1050-1058.

31. Christofidou-Solomidou M, McDonough J, Scherpereel A, Wiewrodt R, Argyris $\mathrm{E}$, et al. (2001) Immunoconjugates of catalase attenuate radiation-induced pulmonary fibrosis in C57bl mice. Int J Radiat Oncol Biol Phys Proc ASTRO.

32. Kinniry P, Pick J, Stephens S, Jain D, Solomides CC, et al. (2006) KL4 surfactant prevents hyperoxic and LPS-induced lung injury in mice. Pediatr Pulmonol 41: 916-928.

33. Christofidou-Solomidou M, Tyagi S, Pietrofesa $R$, Dukes $F$, Arguiri $E$, et al. (2012) Radioprotective role in lung of the flaxseed lignan complex enriched in the phenolic secoisolariciresinol diglucoside (SDG). Radiat Res 178: 568-580.

34. Christofidou-Solomidou M, Tyagi S, Tan KS, Hagan S, Pietrofesa R, et al (2011) Dietary flaxseed administered post thoracic radiation treatment improves survival and mitigates radiation-induced pneumonopathy in mice. BMC Cancer 11: 269 .

35. Pietrofesa R, Turowski J, Tyagi S, Dukes F, Arguiri E, et al. (2013) Radiation mitigating properties of the lignan component in flaxseed. BMC Cancer 13: 179

36. Lee JC, Kinniry PA, Arguiri E, Serota M, Kanterakis S, et al. (2010) Dietary curcumin increases antioxidant defenses in lung, ameliorates radiation-induced pulmonary fibrosis, and improves survival in mice. Radiat Res 173: 590-601.

37. Christofidou-Solomidou M, Scherpereel A, Solomides CC, Christie JD Stossel TP, et al. (2002) Recombinant plasma gelsolin diminishes the acute inflammatory response to hyperoxia in mice. J Investig Med 50: 54-60.

38. Esterbauer H, Schaur RJ, Zollner H (1991) Chemistry and biochemistry of 4-hydroxynonenal, malonaldehyde and related aldehydes. Free Radic Biol Med 11: 81-128.

39. Machtay M, Scherpereel A, Santiago J, Lee J, McDonough J, et al. (2006) Systemic polyethylene glycol-modified (PEGylated) superoxide dismutase and catalase mixture attenuates radiation pulmonary fibrosis in the $\mathrm{C} 57 / \mathrm{bl} 6$ mouse. Radiother Oncol 81: 196-205.

40. Mao XW, Pecaut MJ, Stodieck LS, Ferguson VL, Bateman TA, et al. (2013) Spaceflight Environment Induces Mitochondrial Oxidative Damage in Ocular Tissue. Radiat Res 180: 340-350.

41. Johnston CJ, Williams JP, Okunieff P, Finkelstein JN (2002) Radiation-induced pulmonary fibrosis: examination of chemokine and chemokine receptor families. Radiat Res 157: 256-265.

42. Davis WB, Rennard SI, Bitterman PB, Crystal RG (1983) Pulmonary oxygen toxicity. Early reversible changes in human alveolar structures induced by hyperoxia. N Engl J Med 309: 878-883.

43. Christofidou-Solomidou M, Pietrofesa R, Arguiri E, McAlexander MA, Witwer KW (2014) Dietary flaxseed modulates the miRNA profile in irradiated and non-irradiated murine lungs: a novel mechanism of tissue radioprotection by flaxseed. Cancer Biol Ther 15: 930-937.

44. Shay JW, Cucinotta FA, Sulzman FM, Coleman CN, Minna JD (2011) From mice and men to earth and space: joint NASA-NCI workshop on lung cancer risk resulting from space and terrestrial radiation. Cancer Res 71: 6926-6929.

45. Weil MM, Ray FA1, Genik PC1, Yu Y2, McCarthy M2, et al. (2014) Effects of $28 \mathrm{Si}$ ions, $56 \mathrm{Fe}$ ions, and protons on the induction of murine acute myeloid leukemia and hepatocellular carcinoma. PLoS One 9: e104819.

46. Kulkarni AD, Yamauchi K, Sundaresan A, Ramesh GT, Pellis NR (2005) Countermeasure for space flight effects on immune system: nutritional nucleotides. Gravitational and space biology bulletin: publication of the American Society for Gravitational and Space Biology 18: 101-102.

47. Kennedy AR, Ware JH, Guan J, Donahue JJ, Biaglow JE, et al. (2004 Selenomethionine protects against adverse biological effects induced by space radiation. Free Radic Biol Med 36: 259-266.

48. Nuth M, Kennedy AR (2013) Mitigating effects of L-selenomethionine on lowdose iron ion radiation-induced changes in gene expression associated with cellular stress. Oncol Lett 6: 35-42.

49. Wambi CO, Sanzari JK, Sayers CM, Nuth M, Zhou Z, et al. (2009) Protective effects of dietary antioxidants on proton total-body irradiation-mediated hematopoietic cell and animal survival. Radiat Res 172: 175-186.

50. Mason JK, Thompson LU (2014) Flaxseed and its lignan and oil components: can they play a role in reducing the risk of and improving the treatment of breast cancer? Appl Physiol Nutr Metab 39: 663-678. 
Citation: Pietrofesa RA, Solomides CC, Christofidou-Solomidou M (2014) Flaxseed Mitigates Acute Oxidative Lung Damage in a Mouse Model of Repeated Radiation and Hyperoxia Exposure Associated with Space Exploration. J Pulm Respir Med 4: 215. doi:10.4172/2161105X.1000215

51. Bommareddy A, Arasada BL, Mathees DP, Dwivedi C (2006) Chemopreventive effects of dietary flaxseed on colon tumor development. Nutr Cancer 54: 216222.

52. Bommareddy A, Zhang XY, Kaushik RS, Dwivedi C (2010) Effects of components present in flaxseed on human colon adenocarcinoma Caco2 cells: Possible mechanisms of flaxseed on colon cancer development in animals. Drug Discov Ther 4: 184-189.

53. Hales KH, Speckman SC, Kurrey NK, Hales DB (2014) Uncovering molecular events associated with the chemosuppressive effects of flaxseed: a microarray analysis of the laying hen model of ovarian cancer. BMC Genomics 15: 709.

54. Eilati E, Bahr JM, Hales DB (2013) Long term consumption of flaxseed enriched diet decreased ovarian cancer incidence and prostaglandin Eâ,,in hens. Gynecol Oncol 130: 620-628.
55. Azrad M, Vollmer RT, Madden J, Dewhirst M, Polascik TJ, et al. (2013) Flaxseedderived enterolactone is inversely associated with tumor cell proliferation in men with localized prostate cancer. J Med Food 16: 357-360.

56. Anscher MS, Vujaskovic Z (2005) Mechanisms and potential targets for prevention and treatment of normal tissue injury after radiation therapy. Semin Oncol 32: S86-91.

57. Rabbani ZN, Batinic-Haberle I, Anscher MS, Huang J, Day BJ, et al. (2007) Long-term administration of a small molecular weight catalytic metalloporphyrin antioxidant, AEOL 10150, protects lungs from radiation-induced injury. Int J Radiat Oncol Biol Phys 67: 573-580.

58. Kondrikov D, Elms S, Fulton D, Su Y (2010) eNOS-beta-actin interaction contributes to increased peroxynitrite formation during hyperoxia in pulmonary artery endothelial cells and mouse lungs. J Biol Chem 285: 35479-35487. 